\title{
Lived Experiences of Middle Level Leaders in the Nepali Institutional Schools
}

\author{
Narayan Prasad Kafle* \\ School of Education, Kathmandu University, Lalitpur, Nepal
}

\begin{abstract}
This paper explicates the contextually embedded meaning of being middle level leaders in the Nepali institutional schools. Using in-depth interview and protocol writing as the means of data generation, this article unearths the experience of three middle level leaders. Distributed leadership theory (Spillane, 2006) and its constructs of leadership plus aspect and leadership practice aspect provide the theoretical lens to unveil the myths and realities of being middle level leaders. All three participants shared their common acknowledgement about the significance and sensitivity of middle level leadership roles for school administration and effectiveness. Individual essence of being a middle level leader was contingent on the very context where they worked. Their feelings of being relegated and marginalized, helplessness or high exhilaration were subjects to the contextual reality.
\end{abstract}

Keywords: middle level leaders, lived experience, phenomenology, educational leadership

\section{The Context}

The school principal as an educational leader has been the agenda of research and many modules and taxonomy of principal leaders have been designed and prescribed for practice. Other leaders like vice principal, coordinators, in-charges, on the other hand, have been rather neglected in the research agenda. But in practice, they shoulder the entire burden of school operation and play the liaison role between the school establishment and the rest of the school stakeholders.

According to the Department of Education (DoE) (2012), the school education system of Nepal constitutes four main levels, viz. primary, lower secondary, secondary and higher secondary. Through its School Sector Reform Plan (2009-2015) the government has proposed to change this four tier system into two tiers as basic (grades 1-8) and secondary (grades 9- 
12). However, because of the situation of political transition in the country, this proposed system is yet to be formalized. From the perspective of governance and management, schools in Nepal are classified as: community schools (supported by the government) and institutional schools (established mainly as private sector investment, hence commonly known as private schools). Community schools are basically managed by the government though there is the provision of school management committee (selected/elected by the parents) in each school for day to day management. On the other hand, institutional or private schools are managed by themselves (investors/trustees) and they do not receive any financial, managerial or other educational supports from the government. Institutional schools, however, are required to follow the government rules and regulations. For example, they have to follow the government prescribed curriculum and textbooks and the students in these schools have to appear School Leaving Certificate (SLC) Examination, a national level examination conducted by the government at the end of grade ten. In addition to these two types of schools (community and institutional), there are also some religious schools, such as Madrasa, Gumba/Bihar and Ashram/Gurukula (DoE, 2012) but they are very few.

In the Nepali context, it is only in institutional schools where there are self created provisions for middle level leaders like vice principal, coordinator, and in-charge but these designations or leadership positions are not identified or recognized by the acts, rules and regulations governing the Nepali education system. This means there is no legal provision governing the role and responsibilities of other middle level leaders and it is the individual school's decision whether to have or not to have such positions.

The major issue that builds the foundation for this paper is the experince of being middle level leaders. What does it mean to be a middle level leader? How much empowered are our middle level leaders in reference to their task execution? How do they explain and interpret their own status of being the middle level leaders? How do these middle level leaders make meaning of the activities they perform? Since most of our institutional schools have different middle level leadership posititons, their understanding about their own roles and expericences have a great significance in their own work motivations. This study would therefore help to illuminate the contextual understanding of being middle level leaders in the Nepali institutinonal schools.

Journal of Education and Research, August 2013, Vol. 3, No. 2 


\section{Middle Level Leaders in the Literature of Educational Management}

The roles and responsibilities of teacher leaders positioned at different levels are frequently changing as the impact of change is quickly realized in school organizations (Cranston, 2007). There have been many studies in the area of school leadership, particularly focusing on the principal leaders but the researches typically conducted taking the assistant principals, deputy principals or vice principals are very scanty and the available researches on school leadership overlooked the roles and responsibilities of other leaders including the vice principals and other middle level leaders (Marshall \& Greenfield, 1985; Ribbins, 1997; Muijs \& Harris, 2002; Gunter, 2005; Weller \& Weller, 2002 ). Nevertheless, the emergence of distributed leadership and the growing criticism for one person supremacy have paved new foundations for the researchers to explore more in this area.

Out of those few studies conducted taking assistant principals or middle level educational leaders in school organization, Mertz and McNelly (1999) and Cranston (2007) attributed the emergence of studies on middle level leaders not because of any planned and careful practice but fundamentally due to the growing school population and principals' failure to oversee the entire activities alone.

Confirming the focus on principals as school leaders despite the recognition of shared leadership for school success and effectiveness, Kwan (2009) mentioned it to be a paradox not to pay extensive attention to middle level leaders who are the actual recipients of distributed model of leadership. Marshall (1992) traced the reasons for the presence of middle level leaders in the form of assistant principals or vice principals by pointing out two primary reasons. First, "it is a frequent entry-level position for administrative careers" and the second, "assistant principals maintain the norms and rules of the school culture" (p. 2). This declaration for the emergence of vice principals seems very valid even in our context where now it has been a common tendency to give space to different middle level leaders like vice principal, coordinator, in-charge and head of the department in the organogram of the institutional schools in particular. Along this line, Glanz (2004) maintained the towering significance of vice principals when he stated assistant principalship as a vital resource for instructional improvement and overall school success but at the same time indicated the paradoxical reality of middle level leaders who are bound to be confined within the limited functions of every day administration rather than practicing instructional side of leadership roles. 
Marshall (1992) made a very realistic interpretation of the designation - assistant principal - roles when he mentioned "assistant principals do what the principals don't want to do" (p. 16). It refers to a very pathetic condition of vice principals who are subject to carry out the tasks that the principals normally do not prefer doing. As the adjective 'assistant' itself connotes a meaning of 'one that assists', 'the helper', 'the aide', it is basically generalized that the vice principals are not meant to do anything on their own but to work as asked by the principal. Hartzell (1993) also considered it natural to exhibit the gap in being a principal leader and a vice principal or a middle level leader in reference to organizational theory that automatically places vice principals in the lower strata in the organizational design. Agreeing with Marshall's (1992) etymological interpretation of assistant principals and Hartselle's (1993) organizational design perspective of assistant principals, Cranston, Tormans, and Reugebrink (2004) observed "assistant' is a job title that simply implies "a subordinate, relational and dependent role to another individual, and may not fully acknowledge the qualifications, expertise and experience held by those in such positions" (p. 230).

Some researchers viewed and elaborated the position of a middle level leader as a potential position for career growth to the principalship and made some recommendations for the middle level leadership position holders to utilize this opportunity for future shake. Weller and Weller (2002) optimistically elaborated the position of middle level leaders like assistant principals to be a position of plenty of opportunities and recommended that the existing middle level leaders used their leadership roles for the future preparation of principalship roles. Similarly, Pounder and Crow (2005) stated that the latest developments in leadership theory in education call for school leaders to pursue the distributive approach by creating collaborative leadership teams where there is no one superior as such and the principal delegates her/his authority to her/his subordinates and leads the school as a team. In this approach, the serving principal needs to involve assistant principals in other aspects of school operations beyond just oversight of student discipline. Bolman and Deal (2002) also partly agreed with this proposition of 'middle level leadership as an opportunity for future' and yet maintained that the current existence of being vice principals is quite tough and unrewarding, confined to everyday petty tasks like supervising, managing disciplines, and doing regular fix up jobs. But it ultimately ends up with positive pay off when it becomes the foundation for future preparation of principalship. 
Another important facet of literature that discusses the notion and practice of being a vice principal is about the job position of vice principals and the level and intensity of motivation attached to it. In a research conducted on 331 vice principals of Hong Kong, Yu-kwong and Walker (2010) concluded that the vice principals who were the aspirants of principalship exhibited a higher level of professional commitment, a better sense of efficacy, and experienced a lower level of stress about the job complexity they performed in comparison to those who were not the aspiring candidates or had not anticipated the possibility of being the principal.

From the above discussion what can be inferred is the fact that the leadership roles of the vice principals are quite blurred and they are limited to everyday activities of the school affairs with little or almost nil chance of being positively credited for their tasks. Vice principalship from this perspective is one of the least preferred job titles. From the positive side, being a vice principal is the preparation for future principal leadership - an opportunity to learn and know the pitfalls and ditches of school leadership practices firsthand.

After going through various literatures exploring different dimensions of the vice principal as a middle level school leader, it is obvious that the studies on middle level leaders are quite sparse and the available studies are also limited to the exploration of job satisfaction and measuring the position as a post of transition for the principalship. There has been no substantive studies that attempt to unearth the lived experiences of vice principals as middle level leaders. Furthermore, whatever studies have been done, these are all based on the Western contexts. There is no study in the Nepalese context that explores the essence of being a vice principal.

This study, thus, is original in its own and it contributes to fill the gap in this genre of study by coming up with some valuable constructs that speak the lived experiences of middle level leaders. This study also prepares foundations to carry on similar studies like this that promote the understanding of being middle level leaders in different educational set ups and positions.

\section{Distributed Leadership and Middle Level Leaders}

The emergence of distributed leadership attributes to the failure of one person supremacy in educational administration and acknowledges that leadership in educational establishments prevails at all levels. It offers leadership role to everyone in the organization (Elmore, 2000; 
Gronn, 2000; Spillane, 2006; Harris, 2008). The theoretical frame used for the interpretation of this study comes from the notion of distributed leadership as proposed by Spillane (2006) which acknowledges the work of all individuals working within an organization as the work of leaders whether or not they are formally given any roles, provided with a post or defined as leaders. It believes in the idea that an organization is constituted with multiple leaders and the leadership functions are shared by many.

There are two major domains of distributed leadership. They are: a) leadership plus aspect and b) leadership practice aspect. Leadership plus aspect refers to the presence of more than one person in leadership roles and the leadership practice aspect takes into account the inclusion of these multiple leaders in the process of decision making. So, the middle level leaders do make an important space in reference to the leadership plus aspect and the presence of middle level leaders is a first level indication about the presence or absence of distributed leadership in a particular school set up.

\section{Methodology}

In order to illuminate the lived experience of being middle level leader(s), this study adopted an in-depth interview model and protocol writing by the research participants as the means of data collection where three middle level teacher leaders from three different institutional higher secondary schools of Kathmandu valley were selected as the research participants. All the schools consulted were institutional schools where the Board of Directors (BOD) was the highest decision making body. School Management Committee (SMC), which is the prescribed decision making body by the education act (Ministry of Education and Sports, 1971), came in the second order after the BOD. Moreover, all research participants were male and serving in the institution for more than three years in the capacity of middle level leaders. The data were collected during the months between March and August (2012).

This study adopted hermeneutic phenomenology to illumine the meaning of lived experiences of middle level leaders. Phenomenology best suits to excavate the lived experiences of middle level leaders from both methodological and philosophical perspectives because phenomenology is acknowledged as a method rooted in the concept that through inquiry, one may move past awareness of things, experiences or understandings to arrive at the very essence of the thing itself or the phenomenon (Creswell, 2007). Shank (2002), 
Dahlberg (2006), Gribch (2007), and Langdridge (2007) all agreed to the practicality of a phenomenological research as a way to penetrate down to the crux of human experience and interpret the meaning of being or experiencing a phenomenon in true spirit by terming it to be a useful method to uncover the meaning of an individual's experience, as an approach to understand the hidden meanings and a method used to uncover the nectar or true being of a phenomenon.

According to van Manen (1997), there is no fixed set of rules to conduct the phenomenological research. But as this is a variant of the qualitative research, I used purposive sampling with information rich cases as suggested by Merriam (1998). As the purpose of such study is to generate the life-world stories of the research participants, I used two major qualitative methods, namely interview and protocols, for data generation. Protocols are the writings of the research participants as a direct account of a personal experience as the writer lives through it. These protocols then become important data source for the researcher (van Manen, 1997, p. 63). The data obtained through the interview and protocol were analyzed using the wholistic or sententious approach (van Manen, 1997, p. 92) attending the text as a whole and identifying the sententious phrases that capture the fundamental meaning of being middle level leaders. The representative expressions from the interview and protocol are kept in the text blocks and discussed inductively.

To report the study, an informal but strong metaphorical narrative has been employed. Ethical measures were strictly followed by maintaining the rights of secrecy through the application of the code technique which conceals the names of the participants and their institutions. The policy of no harm was maintained at all times. All the interviews were conducted at the time and venue of the participants' choice and they were informed earlier about the purpose of the study. The protocol writing sheet was provided to the participants and collected a week after. Along with the ethical standards for qualitative research proposed by Creswell (2007), who mentioned assigning aliases to the participants to protect their privacy, clarifying the purpose and procedure of the research beforehand, obtaining informed consent, not disclosing the identities of participants and places, and a number of other ethical practices are applied that include the strict adherence to the ethics of care, and confidentiality. Moreover, the research findings were also shared with the participants. 


\section{Lived Experiences of Middle Level Leaders}

The term lived experience is defined as "the breathing of meaning" (van Manen, 1997, p. 36). It intends to reflect the original feelings of the participant. Here, the term is used to describe the first-hand accounts and impressions of living as a member of a community, a team or an organization. The major question posed for the participants of this study to reflect upon was 'What does it mean to be a middle level leader?' Here follows the presentation of what the participants said and subsequent discussion of each of the expressions they made during the conversation. Some of these live texts come from the protocols that the participants wrote.

The first participant of this study, a young gentleman in his early thirties, who has been working as a vice principal for five years, is the first man in contact with the visitors, parents and students. The school he has been working as a middle level leader is an institutional school with a large number of shareholders. As a vice principal, he reaches the school earlier than others and remains busy throughout the day dealing with students, teachers, reporting to the principal and doing other administrative works and leaves the school at last. At the time he was consulted for the interview, he had just finished his instructional class in grade ten where he taught Social Studies. During the interview process, he seemed restless and all the time peeped outside as if someone was spying on what he had been discussing. He responded to the experience of being a middle level leader with the following remarks:

To be a middle level leader is to be a bridge between the teachers and the administration. My role is the zone of tension among teachers' aspirations and the management's pressure to compromise. What I do is I just forward the concerns to the desk of the principal or in other terms I work as a medium or act to channel the issues to the desk of the principal and what happens after that I really don't know. I consider that being a VP is a type of ladder to be upgraded to the upper position. It is an opportunity for gathering experience. (Participant I)

The participant here uses the metaphors of bridge, zone of tension and ladder to reflect on his role of a vice principal. Two of the metaphors, i.e. 'bridge' and 'ladder' confer the positive message whereas 'zone of tension' refers to the negative side of being a vice principal. There are both opportunities and challenges in being a middle level leader. The positive side of being the vice principal is the possibility to excel ahead and prepare oneself 
for the future leadership role that positively aligns with what Weller and Weller (2002) mention as the position of plenty of opportunities. It is the motivation factor or the boaster for the vice principal to keep on going. At the same time, when he is circled amid a host of roles to play, he finds himself in confusion and tensions and feels being sandwiched between the teachers' aspirations and management's pressure. Consequently, he characterizes his own position as a 'zone of tension' and surrounded by all time conflicts. This stressful experience of the vice principal as a middle level leader matches with Marshall's (1992) referral of vice principals doing what the principals don't want to do. It is in its true essence of being an 'assistant' principal where one has no space for innovation and freedom to make and take decisions but is just bound to perform all those everyday administrative routine tasks that are always de-motivating. When the participant mentions that he just passes the concerns to the desk of the principal or channels up the issues but cannot influence to its execution, it denotes his pathetic and helpless condition. One thing that is quite unique to this conversation is the dominance of positive attributes of being a middle level leader rather than just highlighting the negative aspects of it.

From the perspective of distributed leadership theory (Spillane, 2006), it can be noted that the school has the system of following the leadership plus action with the presence of different leaders at different positions with different roles as meant by their posts such as vice principal, junior wing coordinator, discipline in-charge, and Extra Curricular Activities (ECA) in-charge. However, the middle level leaders in this school including the vice principal are not provided with enough authority, they have no space in the decision making settings like that of the SMC and Board Meetings but they are just asked to carry out the works as assigned by the principals or other top level leaders.

While questioned about the reason for still working in the capacity of vice principal at a work station where there is almost zero possibility of being promoted into the higher position amid such a pressure, this middle level leader shared:

Everybody desires to be promoted to a higher post. I am not exception to this case. Definitely, I want to be a very good vice principal today and principal tomorrow and I am trying to get a wide variety of experiences at this school. As a vice principal I have been gaining some leadership quality as well. So definitely I aspire to be in the post of 
principal in the days to come. For that, I have to build up personnel and leadership capacity accordingly. (Participant I)

It is the aspiration of reaching higher in the leadership strata that motivates one to keep on doing what may sound difficult and de-motivating at the moment. For the futuristic optimism of developing career in the field, not necessarily right there where he is working at the moment, he seems using the opportunity for preparing oneself ready to take up leadership roles for the future. In reference to the research findings on middle level leaders, this hope or optimism confirms with Weller and Weller (2002) and Bolman and Deal (2002) who consider the middle level position as the position of futuristic opportunities and optimistically recommend the existing middle level leaders to take this position as an opportunity to prepare for future principal leadership roles. Metaphorically, this aspiration resembles a popular leadership proverb expressed by Napoleon Bonaparte (1769-1821) that reads 'a leader is a dealer in hope'. It is this ray of hope, the possibility of assuming top leadership role that fuels and keeps the hope of progress flaming even in times of difficulty.

The second participant of the study was a young man in his mid twenties working as a coordinator for four years. The school where he worked was in financial problem and the principal leader was most of the time out of school campus for collecting resources. At the time of the interview with him, he had just come to his office by inspecting the terminal examinations and seemed in a relaxed mood to discuss with the researcher. He conferred the post of coordinator as a post requiring a $3 \mathrm{D}$ vision when he remarked:

For me being a coordinator is a post having a rectangular relationship with administrators, students, teachers and parents/guardians. It is a post requiring $3 D$ eyesight where one should be able to see all the directions at the same time. Balancing the role is the key to being a coordinator, a proper balance among and between the administrator, teachers, students, and parents /guardians. It can be a stepping stone to higher strata in future. (Participant II)

Defining his job from a relational perspective, Participant II maintained that being a middle level leader is all about having a balanced relationship with the three major domains of school organizations, i.e. the administration, the students/teachers and the parents/guardians. Characterized as 'the tricky triangle' by Winter (2006), the notion of this triangular relationship among the key stakeholders of educational life world is the area of 
major concern for the middle level leaders. Transcending from the two dimensional outlook of school affair, this participant advocates that a middle level leader requires to possess multidimensional outlook and requires to be very cautious and attentive to all aspects of school administration. Despite his requirement to tussle with everyday business, he finds the job of being a coordinator to be quite rewarding in a sense that it can be a step for higher leadership positions in days to come. This optimism of the participant confirms what Bolman and Deal (2002) term middle level leadership position to be 'a position with bumpy route but with a cozy destination'.

Though this participant perceives the notion of middle level leadership as a very thriving position with multiple avenues waiting ahead, he expresses his utter dissatisfaction with his particular position at the moment. He finds his position to be quite bizarre with no exit point and scorns the administration for remaining indifferent to the issues raised by him. Applying the tone and diction of utter dissatisfaction, he mentioned:

I am a leader here technically, just because of the absence of the main leader. I am in a position of hanging in a rope looking the garbage down. Neither I can leave the rope nor can I ascend. I have to do everything, yet I am credited for nothing. Leadership here for me is performing everyday activities just trying to see not to let the things go wrong.

\section{(Participant II)}

The major reason for this leader to be that much critical to the school establishment is due to the indifferent nature of the first level school leader who in words has delegated the authority but in practice this participant can take no decision. He is not credited for anything. He has just been relegated to performing the everyday tasks alone. This feeling of relegation would probably contribute negatively to his job performance as management practices have justified the fact that happy employees are productive employees and the employee attitudes typically reflect the morale of the organization itself (Sageer, Rafat, \& Agarwal, 2012). For him, the position being the coordinator is quite enigmatic. This participant consoles himself for his limitations using the metaphorical comparison of hanging in a rope facing the garbage down preventing him to descend and forcing him to continue doing what he has been doing.

The coordinator here simply assumes oneself as a technical leader because of the absence of the main leader. He mentions his job as a management function of doing things right (fixing) against the leadership function of doing right things (innovating) (Lunenburg, 2011). 
This referral of fixing up things and just not letting the things go wrong positions this middle level leader at a stake and prevents him from exerting the leadership behavior that promotes excellence.

The third participant of this study was a gentleman in his late thirties and was quite excited about sharing his experience of being a middle level leader at a time when the executive chairperson or the head of the school was on leave for five days. He had been performing the role of vice principal in that school for the last five years and he was one of the investors as well. This participant shared his office with the executive chairperson of the school and actively participated in all decision making meetings with the school head. Out of the three participants who shared their experience of being a middle level leader, this participant reflected a sense of much satisfaction with his own role and expressed that educational institutions could not try other options but must adhere to the principles of shared leadership. Expressing his joy of being a middle level leader, he firmly mentioned that it was the role of a tactician that required multiple intelligences all at the same time. Clarifying his experience of being a middle level leader, he mentioned:

As a vice principal, I am having a different and unique experience here. The executive chairperson (top level leader) and I sit together, discuss the issues and take collective decisions and confidence of all and implement them. Being a vice principal what I require most is the interpersonal and communication skills along with a better understanding of negotiation skills. I am enjoying what I am doing here as a vice principal. (Participant III)

When Participant III claims that he has a different experience of being a vice principal here, he is clearly indicating the fact that in many cases the job of a vice principal is not as pleasing as he has been enjoying there. Since he has ample opportunity to sit together and discuss with the top level leader and make a collaborating decision, he finds it quite comfortable to execute the decision. Here too the main essence of being the vice principal is administering the decisions but the difference here is that he has the role in the process of decision making. From the viewpoint of Spillane (2006), in this case, distributed leadership is the perfect execution of the leadership plus and leadership practice aspects. Here the environment is conducive enough at least for him if not for others to participate in the decision execution process as well. This situation is favorably aligned with two factors 
associated with being the vice principal, i.e. an entry level administrative position and maintaining norms and rules of the school culture (Marshall, 1992).

This inspiring work environment of this vice principal has enabled him to express a very optimistic thought about the teaching profession as a whole. Along this line, he stated:

Teaching is a noble job. Everyone must try at least once in their life time. Doing everything alone is not all possible, not is it productive. I trust others. I am like a middle manager maintaining the link between teachers, in-charges, students and the management. For me it is the job, I feel I am born to perform. Trusting others, inspiring others; it is all about coordinating and collaborating than controlling. (Participant III)

Participant III believed in team work and his understanding of teaching as a noble profession, as he claimed, will pave the foundation for him to grow ahead. This stimulates him for the higher level of motivation and contributes to discharging his responsibilities in close collaboration and proximity with others wining their confidence not through coercion or the influence of position power. It generates trust and mutual understanding. It adds to the thesis that how the leaders experience is contingent on the leadership structure and the work environment. This high level of job motivation and the performance of the vice principal confirm to what Yukwong and Walker (2010) stated as the characteristics of the aspirant principals. Though not all vice principals and other middle level leaders are privileged to get such an environment, he is the true recipient of the fruits of distributed leadership as proposed by Spillane (2006), who envisions the environment of coordination, collaboration and collectivity through the application of distributed leadership in the school organizations.

Further highlighting the very reasons for claiming an encouraging work environment and a unique type of leadership practice they have been experimenting in their school, Participant III further remarked:

Considering the existing leadership structure and practices you may not find the grievance of vice-principal in this school. We must give this credit to our chairman since he held this responsibility he has been practicing these sorts of innovative things. Our chairman is the man of action and man of words. (Participant III)

This extraordinary sense of confidence in this middle level leader at a time when the previous two clearly articulated a strong sense of dissatisfaction comes off not only because 
of the leadership plus and practice aspects alone but also from the typical leader behavior as exhibited by the top level leader (Chairman) of the school. The school's overall structure and practice both are friendly for an encouraging and stimulating work environment keeping the moral of all people high, with a changed lens that keeps the human being in center this is what the new science perspective of leadership (Wheately, 2006) calls for. New realities call for new perspective, the leadership behavior and practice aspect need to change to match with the new reality (Stehr, 2001).

\section{The Essence of Being Middle Level Leaders}

From this brief elicitation of responses from the different middle level leaders of Nepali educational enterprises, a range of themes emerged that assisted in drawing some common understanding of being the middle level leaders. The essence is the final product of explication, illumination, disclosure and clarification of the phenomenon under discussion (Dahlberg, 2006).

Participant I of this study desired and attempted to do his very best but the school leadership structure did not seem favorable for him as he experienced being sandwiched between the pressure of the management to compromise and the expectations of his fellow teachers to make some meaningful differences during his tenure. He felt like walking on a double-edged sword where he had to encounter the defying teachers and irresponsive management all at the same time. He felt really helpless to be a middle level leader with no authentic decision making capacity.

Participant II experienced an enigma of being a coordinator but continued gaining experience of it expecting this understanding and experience of being a coordinator would help him prepare to assume higher leadership roles in future. He felt like a disabled person to be in such a hanging position with responsibility devoid of authority.

Participant III, unlike other participants, expressed his exhilaration of being a middle level leader who could connect like a bridge, support like a ladder and moreover he underscored the charm of being a middle level leader as a position that is accessible to all.

All the participants of this study unanimously highlighted the significance of being the middle level leaders for a school organization. They characterized the position of middle level leaders like vice principal and coordinator to be an omnipresent one. This notion of being significant for school organizations constituted the shared experience of being the 
middle level leaders. On the contrary, the actual experience of being the middle level leaders was contingent on the school culture, the leadership structure and their say in the decision making process. Two of the participants felt relegated and marginalized and just kept on hanging around as they had no immediate alternative in the absence of favorable school culture and leadership structure whereas one of the middle level leaders was found to be highly motivated when the work environment was favorable to him.

Except one vice principal who experienced quite high exhilaration and profound sense of contentment in being what he was, other two experienced high level of stress and were not in the mood of elaborating the feats of being the middle level leaders. The thing that haunted them all the time ever was the sense of marginalization. They had to confine themselves with the routine sort of job. They had either very little or no role in the decision making process. The experience of being the middle level leader as of vice principal, coordinator and wing incharges had morphed into a 'jack of all trades' who must deal with multiple responsibilities simultaneously. It was probably due to this haziness that the middle level leaders find themselves pulled in many directions. They were often entangled in inscrutable situations. It all depended on the school culture, leadership structure and the decision making practice. If the leadership plus and practice aspects were in good harmony, middle level leaders would have the opportunity to grow and work in high motivation otherwise it would lead to the feeling of relegation. Where there were motivational measures, the condition was exemplary as Participant III experienced.

The participants characterized the experience of being middle level leaders with metaphors like the zone of tension, bridge, and ladder. Despite having a very tough time and performing a very stressful and challenging job, like a silver lining of the cloud, the participants of this study exhibited a faint ray of hope. They kept on sticking to their jobs despite experiencing traumatic conditions possibly with the hope of situations to improve for them. These unsung heroes worked silently behind the backdrop experiencing a mix of more frustration but little joy. They seemed selflessly contributing to run the school system as if they had metaphorically internalized the very essence of the Bhagavad Geeta, an opus of the Hindu scripture where the great lord preached his disciple the following line:

कर्मण्येबाधिकारस्ते मा फलेषु कदाचन । भागवत गीता ॥ २. ४७॥ 
The literal meaning of this verse according to Maharaja (2010) is "go on doing your duty and don't desire the fruits of your labor" (p. 6). The implication of this verse to the middle level leaders is to keep on performing the responsibilities with holiest of the intentions and without expecting much of their designation. It is an analogy that reflects the ironic experience of being middle level leaders. It is not a line of advice for middle level leaders for keeping on working but an articulation of their fate who are bound to keep on shouldering the everyday responsibilities of the school system, be visible everywhere, accept the debit of failure yet with no clear career growth path and certainty about the future. The presence of distributed leadership in terms of leadership plus aspect only further weakens the middle level leaders who are decorated with the designation but have no authorities to make decisions and participate in the decision making settings.

\section{References}

Bolman, L., \& Deal, T. (2002). Reframing the path to school leadership. Thousand Oaks, CA: Corwin Press.

Cranston, N. (2007). What do we know about middle-level school leaders in New Zealand? An exploratory study of Auckland secondary deputy and assistant principals. New Zealand Journal of Educational Leadership, 22(1), 16-30.

Cranston, N., Tromans, C., \& Reugebrink, M. (2004). Forgotten leaders: What do we know about the deputy principalship in secondary schools? International Journal of Leadership in Education, 7(3), 225-242.

Cresswell, J. (2007). Qualitative inquiry and research design: Choosing among five approaches. Thousand Oaks, CA: Sage.

Dahlberg, K. (2006). The essence of essences - the search for meaning structures in phenomenological analysis of lifeworld phenomena. International Journal of Qualitative Studies on Health and Well-being, 1(1), 11-19.

Department of Education (DoE). (2012). Flash I report 2068 (2011/2012). Sanothimi, Bhaktapur: Author.

DoE. (2012). School level educational status of Nepal: A consolidated report. Sanothimi, Bhaktapur: Author.

Elmore, R. (2000). Building a new structure for school leadership. Washington: The Albert Shanker Insittute.

Journal of Education and Research, August 2013, Vol. 3, No. 2 
Glanz, J. (2004). The assistant principal's handbook: Strategies for success. Thousand Oaks, CA: Corwin Press.

Gribch, C. (2007). Qualitative data analysis. London: Sage Publications Inc.

Gronn, P. (2000). Distributed properties: A new architecture for leadership. Educational Management \& Administration, 28(3), 317-338.

Gunter, H. M. (2005). Leading teachers. London: Continuum.

Harris, A. (2008). Distributed leadership: According to the evidence. Journal of Educational Administration, 46(2), 172-188.

Hartzell, G. N. (1993). The assistant principal: Neglected actor in practitioner leadership literature. Journal of School Leadership, 3, 707-723.

Kwan, P. (2009). Vice-principals' dilemma - career advancement or harmonious working relationship. International Journal of Educational Management, 23(3), 203-216.

Langdridge, D. (2007). Phenomenological psychology: Theory, research and method. Harlow, Essex: Pearson Prentice Hall.

Lunenburg, F. C. (2011). Leadership versus management: A key distinction - at least in theory. International Journal of Management, Business and Administration, 14(1), 1-4.

Maharaja, G. (2010). The essence of the Bhagavad Geeta. New Delhi: Gaudiya Vedanta Publications.

van Manen, M. (1997). Researching lived experiecne: Human science for an action sensitive pedagogy. Ontario: Althouse Press.

Marshall, C. (1992). The assistant principal: Leadership choices and challenges. Newbury Park, CA: Corwin Press.

Marshall, C., \& Greenfield, W. (1985). The socialization of the assistant principal: Implications for school leadership. Urban Education, 18, 3-6.

Merriam, S. B. (1998). Qualitative research and case study applications in education. San Francisco, CA: Jossey Bass.

Mertz, N., \& McNeely, S. R. (1999, April). Through the looking glass: An upfront and personal look at the world of the assistant principal. Paper presented at the annual meeting of the American Educational Research Association, Montreal, Quebec, Canada.

Ministry of Education and Sports. (1971). Education act. Kathmandu: Author.

Muijs, D., \& Harris, A. (2002). Assistant and deputy heads: A review of research. Coventry, UK: The University of Warwick. 
Pounder, D., \& Crow, G. (2005). Sustaining the pipeline of school adminstrators.

Educational Leadership, 62(8), 55-60.

Ribbins, P. (1997). Heads on deputy headship: Impossible roles for invisible role holders? Educational Management and Administration, 23(3), 295-308.

Saari, L. M., \& Judge, T. A. (2004). Employee attitude and job satisfaction. Human Reseource Management, 43(4), 395-407.

Sageer, A., Rafat, S., \& Agarwal, P. (2012). Identification of variables affecting employee satisfaction and their impact on the organization. IOSR Journal of Business and Management (IOSR-JBM), 5(1), 32-39.

Shank, G. (2002). Qualitative research: A personal skills approach. Columbus, $\mathrm{OH}$ : Merrill Prentice Hall.

Spillane, J. (2006). Distributed leadership. San Francisco: Jossey-Bass.

Stehr, N. (2001). Modern societies as knowledge societies. In G. Ritzer \& B. Smart (Eds.), Handbook of social theory (pp. 494-508). London: SAGE Publications.

Weller, D., \& Weller, S. (2002). The assistant principal: Essentials for effective school leadership. Thousand Oaks, CA: Corwin Press.

Wheately, M. J. (2006). Leadership and the new science: Discovering order in a chaotic world (3rd ed.). San Fransisco, CA: Berrett-Koehler Publishers, Inc.

Winter, D. (2006, Autumn). The tricky triangle: Children, parents, and teachers. Research Bulletin, 12(1), 21-24.

Yu-kwong, P. K., \& Walker, A. (2010). Secondary school vice-principals: Commitment, challenge, efficacy and synchrony. British Educational Research Journal, 36(4), 531-548.

Journal of Education and Research, August 2013, Vol. 3, No. 2 